\title{
Teaching for Emergent Disciplinary Drawing in Science? Comparing Teachers' and Children's Ways of Representing Science Content in Early Childhood Classrooms
}

\author{
Sofie Areljung ${ }^{1}$ (D) $\cdot$ Marianne Skoog ${ }^{2} \cdot$ Bodil Sundberg $^{3}$
}

Accepted: 16 November 2021 / Published online: 10 December 2021

(c) The Author(s) 2021

\begin{abstract}
This classroom-based study aims to contribute knowledge about children's opportunities to make use of drawing to make meaning in science. Employing a social semiotic approach to drawing, we examine what ways of representing science content that are (1) made available by the teacher and (2) adopted in children's drawings. We analysed observation data from 11 science lessons in early childhood classrooms (children aged 3 to 8 years), including the drawings that children made during those lessons (129 drawings in total). Our findings suggest that the semiotic resources that teachers provide have a large impact on how children represent science content in their drawings. Moreover, we interpret that teachers strive to support children's 'emergent disciplinary drawing' in science, since they predominantly provided semiotic resources where the science content was generalised and decontextualised. Finally, we propose that 'emergent disciplinary drawing' is incorporated as an element of science pedagogy in ECE practice and ECE teacher education.
\end{abstract}

Keywords Social semiotic theory - Disciplinary literacy $\cdot$ Visual representations $\cdot$ Science education $\cdot$ Early childhood education

\section{Introduction}

There is reason to believe that drawing can play an important role for meaning making in science in early childhood education (ECE). According to science education research, drawing may enhance students' conceptual understanding (Ainsworth et al., 2011), their ability to communicate knowledge (Danish \& Phelps, 2011), and their ability to critically use and interpret visual media (García Fernández \& Ruiz-Gallardo, 2017). Although drawing activities are recurrent parts of science teaching in ECE in many countries, little is known about how children's drawing practices depend on the resources that teachers make

Sofie Areljung

sofie.areljung@umu.se; marianne.skoog@oru.se; bodil.sundberg@oru.se

1 Department of Applied Educational Science, Umeå University, 90187 Umeå, Sweden

2 School of Humanities, Education and Social Sciences, Örebro University, Örebro, Sweden

3 School of Science and Technology, Örebro University, Örebro, Sweden 
available in the classroom. Instead, most research on drawing in ECE science classrooms has focused on the children's drawings per se or on the cognitive abilities of the children who made the drawings (Danish \& Saleh, 2014).

The overarching aim of the article is to contribute knowledge about children's opportunities to make use of drawing to make meaning in science in ECE classrooms. Specifically, we aim to contribute knowledge on if and how the resources provided by teachers influence how children draw in science class.

\section{Social Semiotic Approach to Drawing}

The article employs a social semiotic approach to drawing in the science classroom. In accordance with this approach, we view meaning making as a process in which children reshape information communicated by the teacher in the classroom (Jewitt et al., 2001). Moreover, we assume that one needs to pay attention to the choices that are available to children when they draw in order to understand their opportunities to make use of drawing to make meaning in science (MODE, 2012). Hence, we pay attention to semiotic resources, such as symbols, use of colour, compositions, and drawing techniques, that teachers and peers make available in the classroom, but also on semiotic resources made available in other parts of children's lives, such as symbols and drawing techniques that they pick up from popular culture.

One central aspect of social semiotics is that each cultural context has specific conventions for how to make representations in that context (Kress et al., 2001). For example, the science disciplines biology, chemistry, and physics have their own conventions for drawing (Hoffman and Wittman, 2013). In biology, species should often be drawn with the greatest possible accuracy (Wittman, 2013), whereas in physics, one is usually expected to reduce the complex reality as much as possible when drawing a model (Mešić et al., 2017). Within the different science disciplines, semiotic resources in the shape of specific symbols, colour codes, and structures have emerged. Therefore, a chemistry drawing that may occur abstract to novices conveys much information to those who know how to discern and interpret the visual elements in the drawing (Cooper, Stieff, and DeSutter 2017).

Although drawing in a local ECE classroom is not as specialised as in the science disciplines, we assume that when children draw, they relate to explicit and implicit conventions at play in their classroom. For example, Lundin and Jakobson (2014) interviewed 8 -year-old children about why they included various features in drawings of the human body, made in science class. They found that children were influenced by what is socially appropriate to include, what looks good, what the children are able to draw and what fits into the paper, what they remember to include, and what experiences they have of the topic at hand. Other studies have shown that children's conceptions of 'how to draw in science class' change as they perceive what type of drawing their teacher prefers. In Danish and Saleh's (2015) study, teachers supported 6- to 9-year old children to review each other's drawings of the life cycle and habitat of turtles. Consequently, the children changed their idea of what constitutes a good representation in terms of detail, accuracy, and correct sequence. Monteira (2017) shows that, over a teaching period, 5- to 6-year-olds modified their drawings of snails to include less decorative elements and more accurate details. The change was partly due to their having engaged in systematic observations and partly due to what kind of drawings they perceived that their teacher valued. Correspondingly, Ero-Tolliver, Lucas, and Schaube (2013) note that the 6- to 7-year-old children in their study more 
seldom decorated their science notebooks with hearts and flowers at the end of a teaching period. Judging from the article, the teacher did not explicitly comment on the decorations. However, the teacher's written response celebrated the descriptive qualities of the notebook entries.

In sum, previous studies imply that teachers convey messages on 'how to draw in science class' through classroom dialogue and individual feedback. However, little light has been shed on the semiotic resources that teachers make available to children during lessons in ECE. The current article has the potential to make an important contribution to how teaching influences the choices available to children when they draw in science class, by responding to the following research questions: What ways of representing science content are (1) made available by the teacher and (2) adopted in children's drawings?

\section{Context and Method}

The study is part of a larger project, in which we observed science teaching in eleven ECE classrooms. The project focused on science teaching in general, and we had not indicated any particular interest in drawing to the teachers participating in the study. Hence, we have classroom data showing how drawing tasks play out in science lessons planned by the teacher, which is rare, as most studies of drawing in science in ECE build on teaching designs that were partly or fully controlled by researchers. In total, we have observed 45 science lessons. The current study builds on data from the eleven science lessons, in nine ECE classrooms, where teachers gave children a drawing task (Table 1).

\section{Early Childhood Education in Sweden}

The study was conducted in Sweden, where ECE includes three school forms: preschool (for children aged 1-5 years), preschool class (6 years), and primary school grades 1-3 (7-9 years). Although preschool is voluntary, 85 percent of all children aged 1-5 and 95 percent of the 3- to 5-year-olds are enrolled in preschool (Skolverket, 2019). Preschool class and primary school are compulsory. For the ease of reading, we use the words 'classroom' and 'lesson' to address the context and the activity of the observed science teaching events, although these words are not normally used in relation to Swedish preschool practices.

\section{Participants}

Four of the nine classrooms included in the study were situated in urban areas and five in rural areas. Eight of the teachers have a teaching degree, and one is an educated child minder (barnskötare). In the preschools, 20-25 children were enrolled, many of them part time, why all were not present at the same time. We observed lessons where one preschool teacher was teaching groups of 4-8 children. Meanwhile, the other children were involved in some other activity, which is a common way of organising the daily schedule in Swedish preschools. The preschool classes and primary school classes consisted of 17-23 children. In most of the observed lessons, some children were absent. 


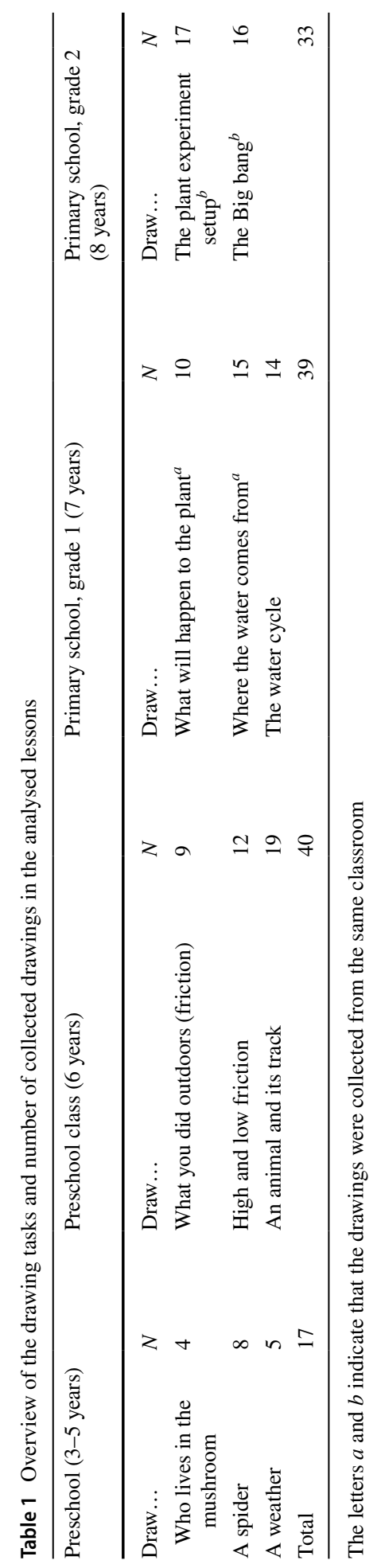




\section{Data Collection}

To respond to the research questions, we use information about semiotic resources provided by the teacher during science lessons (RQ1) and the drawings made by children during these lessons (RQ2).

One, two, or all three authors were present during ten of the eleven lessons included in the sample. One lesson (draw an animal and its track) was observed by our project colleague. During the classroom visits, we made extensive field notes, which include the teachers' verbal instructions to drawing tasks and descriptions of demonstrations made by the teacher. In six of the nine classrooms, we were also allowed to video record the lessons. We took photos of the semiotic resources provided by the teacher during the lesson, such as books and PowerPoint images, and of their drawings and written instructions on the white board. We also photographed drawings that children produced (129 drawings in total). Here, we only included drawings that children considered to be finished at the end of the lesson.

\section{Analytical Procedure}

Our analysis was inspired by Westlund's (2018) tool for sorting out and making sense of children's meaning making in science. Grounded in Kress and Van Leeuwen's (2006) work on modality markers and coding orientation, Westlund proposes that children may represent science content as theory, natural experience, event, art, person, attitudeevoking, and cultural heritage. Westlund bases these categories on an analysis of drawings made by children in grade 2 . They mainly represented concrete objects in science, such as mushroom, stars, and parts of the human body. Our data entails drawings made by children younger than those in Westlund's study, and also representations of processes and abstract phenomena in science, such as friction and the water cycle. We have adapted Westlund's categories by testing them in relation to data in three steps. First, all authors, separately, tested the categories on a class set of drawings, to evaluate the overall potential of the categories in relation to our type of data. We then met to discuss our interpretations of the categories and adjust them before we, again separately, analysed all the drawings in this study, making notes on needs for further adaptations in order to be applicable to the data. Last, we jointly analysed all the drawings, two times, settling for the following meaning of the categories:

- Theory. The science content is reduced to its most general aspects from a scientific point of view, in terms of detail, colour, shape, and setting.

- Context. The science content is placed in a setting, with contextual details beyond the most general scientifically relevant aspects of the content. This category is adapted from Westlund's category natural experience, which refers to the science content being placed in a setting where it is likely to be found. We expand this category to include any drawing where the content is placed in a setting, regardless of whether it is a likely setting for the content.

- Event. The drawings indicate movement or processes. Alignment, contrast, and proximity are used to signal events as well as symbols such as arrows and lines showing speed and movement. 
- Art. The drawings are characterised by vibrant colours, decorative patterns, or experimental shapes.

- Person. The drawings include facial features, body parts, or other human bodily traits, although the science content is non-human.

- Culture. This category is an adaptation of Westlund's category cultural heritage, which refers to the use of visual elements from religion and folklore. As Westlund, we interpret the use of cultural symbols, such as the star and heart, as signals of science as culture. However, we expand this category to include drawings where symbols from popular culture as well as cartoon techniques are used to describe the science content.

Westlund also uses a seventh category, attitude-evoking, to capture signals of children's feelings about the content, for example, by their use of emoticons. We have chosen not to use this category as it did not apply to our data set. Neither teachers nor children represented the science content as attitude-evoking.

In Table 2, we provide examples of how we have used the six categories in our analysis. Like Westlund, we assume that many of the categories may appear in parallel in one representation. For example, a drawing may be categorised as theory as well as art, culture, or event, because we judge that the three latter may encompass conventional, from a science point of view, ways of representing science content. However, in our interpretation, the definition of theory excludes the categories context and person because they indicate that the representation is not reduced to its most general aspects from a scientific point of view, in terms of detail, colour, shape, and setting. Four of the drawings were not possible to assign with any of the six categories, because we could not identify the science content in these drawings. They are still included in the total number of drawings analysed.

\section{Analysis of Resources Provided by the Teacher}

First, we identified which semiotic resources the teacher provided during the lesson. Our focus was on semiotic resources related to visual representation, such as symbols, use of colour, and composition. These resources were either demonstrated by the teachers or provided via templates, photos, books, or webpages. Next, we used the six categories above to analyse how the science content was represented in the semiotic resources.

\section{Analysis of Children's Drawings}

In our analysis of children's drawings, we have assumed that the science content to represent was the content addressed in the teachers' instructions for the drawing task. Our interpretation of how that content was represented was based on what we could infer from the children's drawings. We cannot say what the child intended to draw, and whether the intention was limited by their ability to draw. We are aware that we, to an extent, interpret what children are able to draw (cf. Lundin \& Jakobson, 2014), and not only what the children judge to be appropriate ways of drawing in the classroom context. The issue of what children are able to draw is particularly relevant for the drawings made by the youngest children in our study. However, research has shown that also 
Table 2 Examples of teachers' and children's representations of science content and how they are categorised (inspired by Westlund, 2008)

\begin{tabular}{|c|c|c|}
\hline Drawing & Category & Explanation \\
\hline \multirow{3}{*}{$\begin{array}{l}\text { Vord } \\
\text { Mäniokor } \\
\text { A teacher's drawing on the whiteboard of 'What a plant } \\
\text { needs to survive'. The list includes the words water, soil, } \\
\text { humans, sun, air, manure, seeds, and shadow. }\end{array}$} & Theory & $\begin{array}{l}\text { The list of symbols conveys a } \\
\text { schematic overview of factors } \\
\text { important to plant growth. }\end{array}$ \\
\hline & Culture & $\begin{array}{l}\text { 'Manure' is represented with a } \\
\text { symbol that resembles a well- } \\
\text { known emoji. }\end{array}$ \\
\hline & Event & $\begin{array}{l}\text { The representation of } \\
\text { 'humans' includes a figure } \\
\text { who is watering a flower. }\end{array}$ \\
\hline \multirow{2}{*}{ A child's drawing of the Big Bang. } & Theory & $\begin{array}{l}\text { Displays the most general } \\
\text { aspects of the Big Bang, that } \\
\text { is, an explosion (expanding } \\
\text { materia) against a dark } \\
\text { background. Resembles } \\
\text { illustrations used in } \\
\text { astronomy. }\end{array}$ \\
\hline & Art & Vibrant colours. \\
\hline \multicolumn{3}{|r|}{$\begin{array}{l}\text { The spider has facial features } \\
\text { that are human rather than } \\
\text { spider-like. }\end{array}$} \\
\hline $\begin{array}{l}\text { A child's drawing of where the water in the glass jar } \\
\text { comes from (condensation). The sentence written below } \\
\text { the drawing reads 'The cloud breaks and then there is } \\
\text { blommater sen biet dem gar } \\
\text { water on the flower'. }\end{array}$ & Context & $\begin{array}{l}\text { The experiment setup (glass } \\
\text { jar) is placed in a setting with } \\
\text { contextual details beyond the } \\
\text { relevant scientific aspects of } \\
\text { the experiment, such as grass, } \\
\text { rain cloud, and a tree. }\end{array}$ \\
\hline
\end{tabular}


young preschool children are responsive to social conventions when they draw (夰ggård, 2005), and in our data, we see that preschool children represent the science content in many different ways.

\section{Comparing Resources Provided by Teachers to Children's Drawings}

Finally, we compared the outcome of the analysis of semiotic resources provided by the teachers to the outcome of the analysis of children's drawings. In order to make the comparison, we calculated the percentage of children's drawings that represented the science content as theory, context, art, culture, person and event (Table 3). Thereby, we could see to what extent children represented science content in the same way as in the resources made available by the teacher during the lesson. We could also see what additional ways of representing science content that children adopted in their drawings.

\section{Findings}

In this section, we first present the overarching findings, based on data from all the eleven lessons. Next, we contextualise the findings through stories from three classrooms.

\section{Ways of Representing Science Content in Teachers' Resources and Children's Drawings}

The analysis of observation data reveals that the teachers primarily, in ten of the eleven lessons, provide resources where science is represented as theory, hence as content reduced to its most general aspects in terms of detail, colour, shape, and setting. As shown in Table 3, a large majority of the children mainly represent science content in the same way as in the semiotic resources provided by their teacher.

\section{Association Between Teachers' Resources and Children's Drawings-Stories from Three Classrooms}

Below we seek to contextualise our findings by presenting stories from three lessons. We choose these lessons because they represent three different ways of providing semiotic resources. During the observed lessons, the teachers either provided photographs, templates, or images via books and online sources (row 1-6 in Table 3), drew on the board or on paper (row 7-10), or did not provide any semiotic resources (row 11).

\section{Story 1: Teacher Provides Images from Books and Online Sources}

The first example comes from a preschool-class. In a previous science lesson, the teacher and children had been looking for animal tracks in the snow. In the observed lesson, the teacher showed several illustrated books about animals, discussing some of their content with the children (Fig. 1). Next, the teacher explained that the children would work in pairs and use books to respond to questions about an animal on a template (name of 


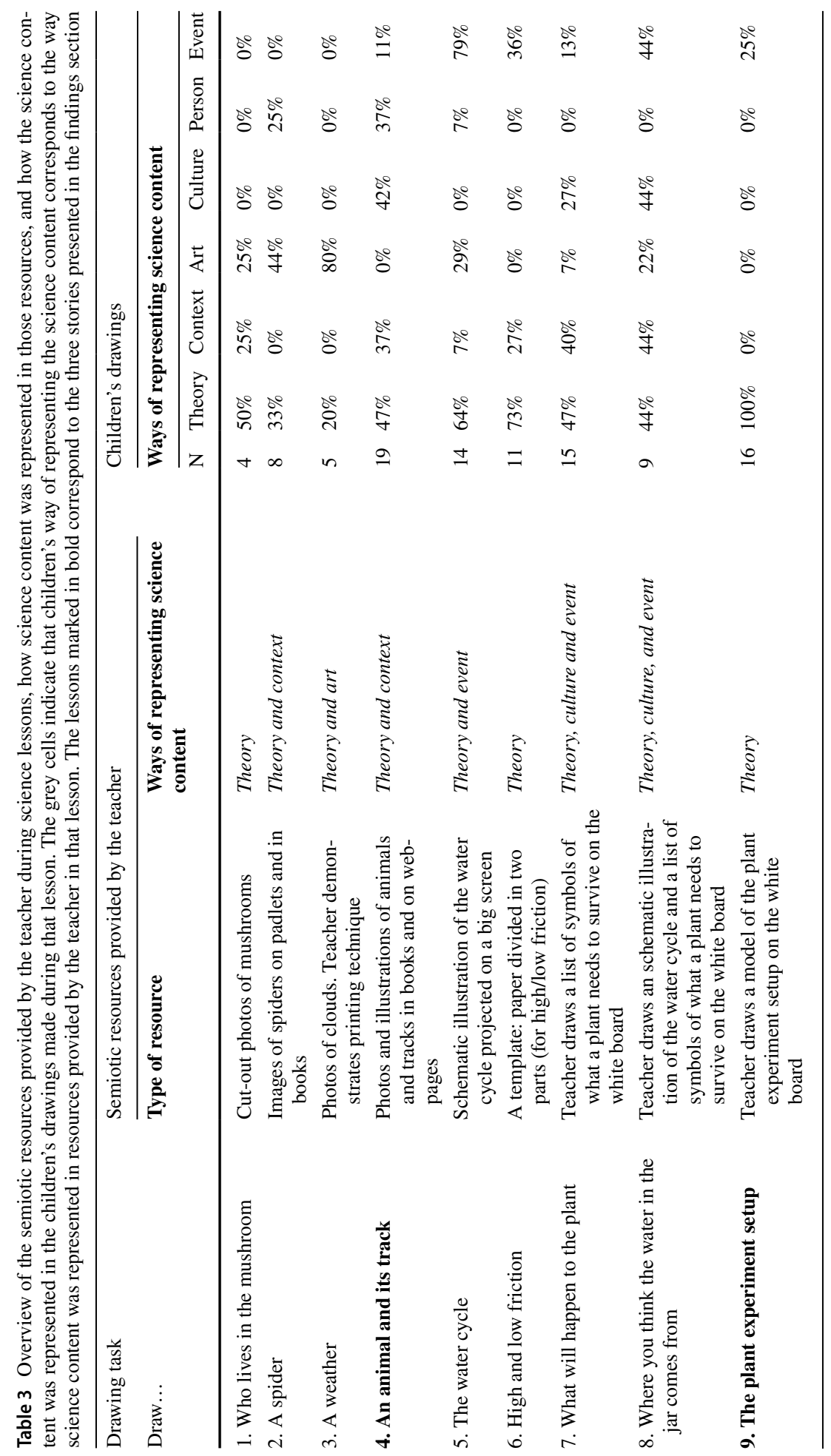




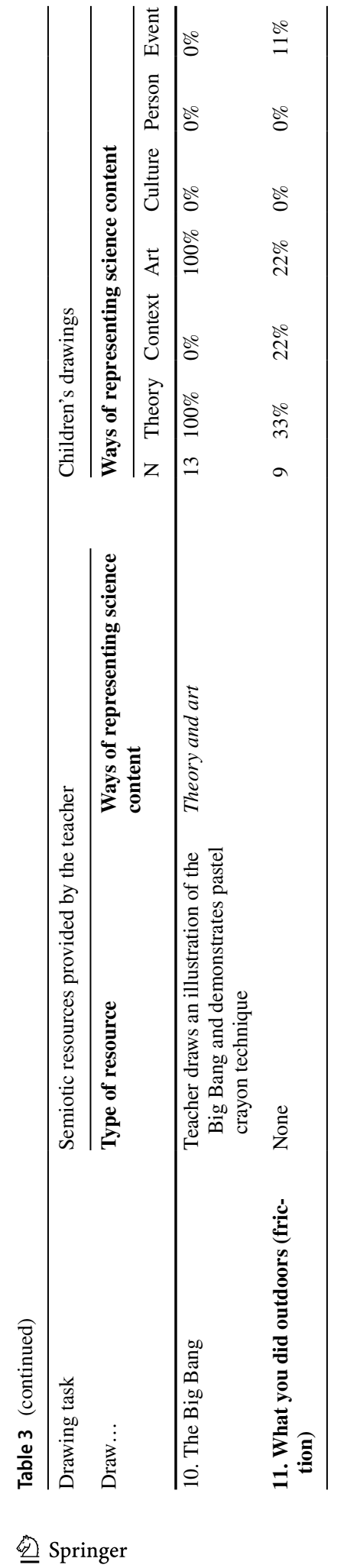


Fig. 1 Teacher shows a book with illustrations of animals and tracks. Categorised as theory

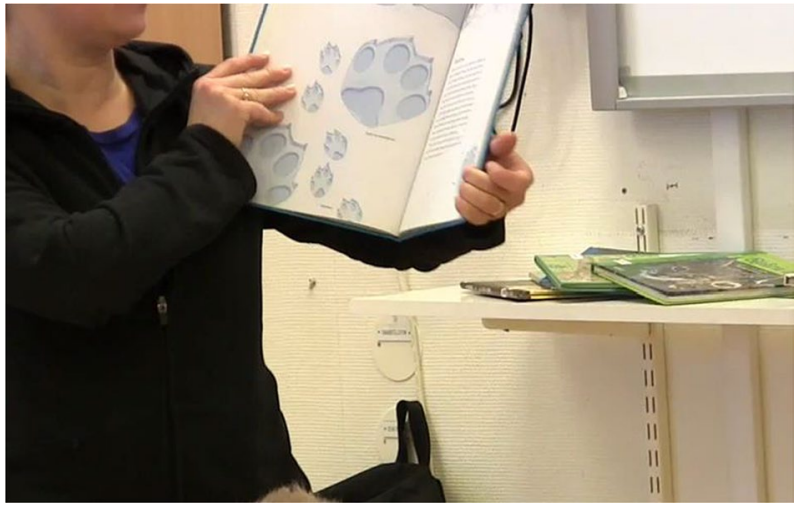

Fig. 2 Teacher browses images of "seal tracks" (sälspår), displaying images of seals in their natural environment. Categorised as context

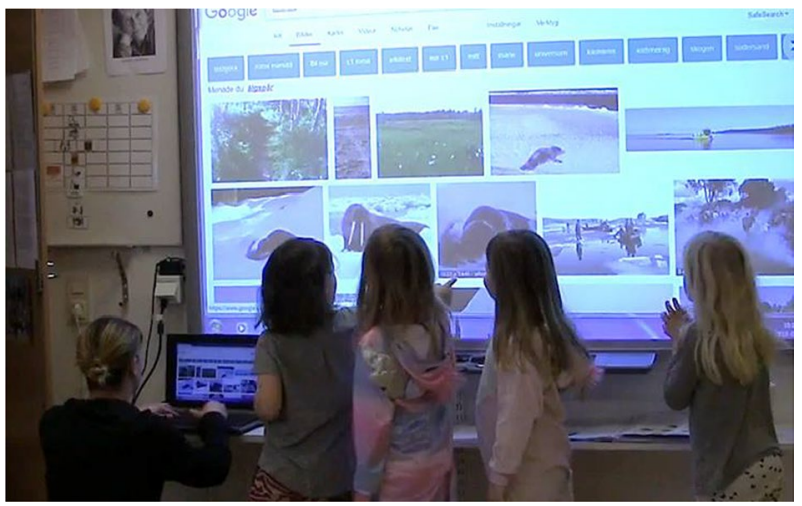

animal, height, weight, where it lives, what it eats, and 'other') before they drew one picture each of the animal and the tracks on a blank sheet of paper. If the needed information was missing in the books, the teacher helped children to look for answers and images online, displayed on a large screen in the classroom (Fig. 2). Since the images in the books and online sources displayed animals and tracks as simplified illustrations or as they could be seen in nature, we categorised them as theory and context.

Altogether, the 19 drawings collected in this classroom represented science as theory, context, culture, person, and event. For example, one drawing of a squirrel and its track (Fig. 3) was interpreted as theory since it displays minimalistic information about the animal and its tracks in terms of detail, colour, and setting. In other drawings, the animals were given human attributes. One such example is a drawing of two dolphins (Fig. 4), which was categorised as person since the dolphins' eyes were drawn with eyelashes. It is also an example of the content being represented as culture because the eyes are drawn in a way that resembles a cartoon technique and since the drawing includes symbols for a star, a heart, and a baby bottle.

\section{Story 2: Teacher Provides a Drawing on the Whiteboard Where the Science Content is Reduced to General Aspects}

The second example comes from a grade 2 classroom. The teacher started the lesson by asking children what plants need to survive. Next, she demonstrated an experiment, putting 


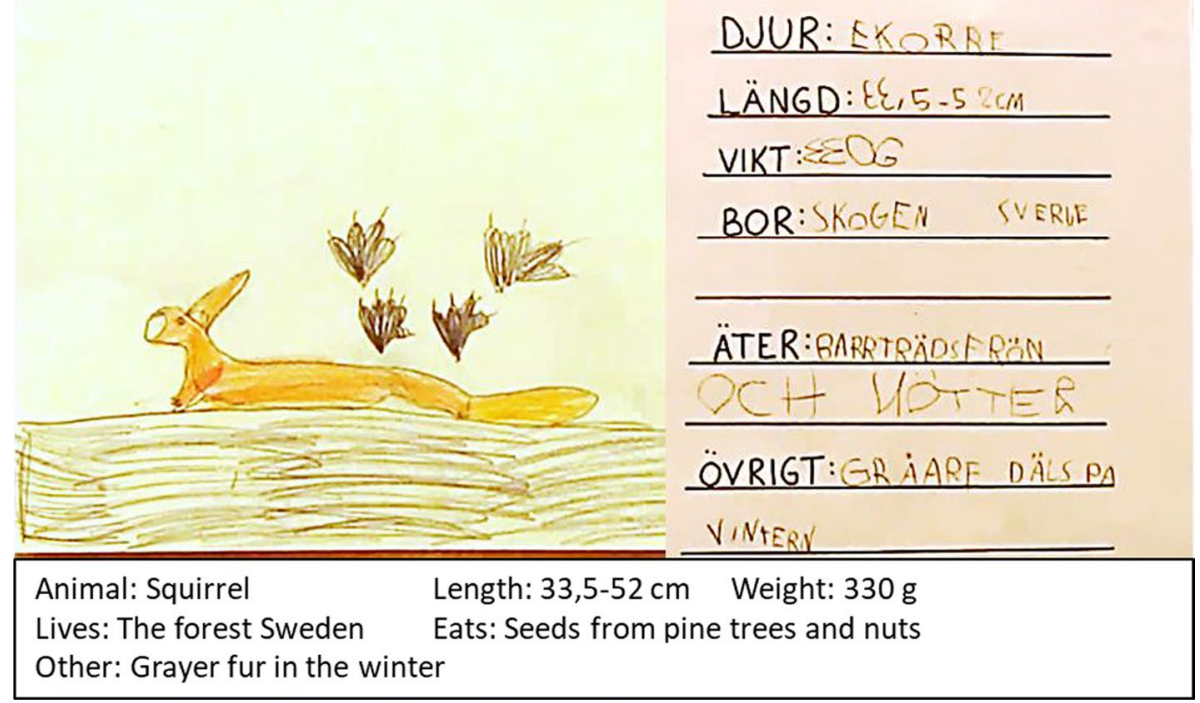

Fig. 3 A child's drawing of a squirrel and its traces. Categorised as theory

DJUK:Deltinen

LÄNGD:1,40 och 4,00

VIKT: $80 \mathrm{KG}$.

BOR: HAVET

ÄTER:Fisk

ÖVRIGT:LEKMEDDELFIN

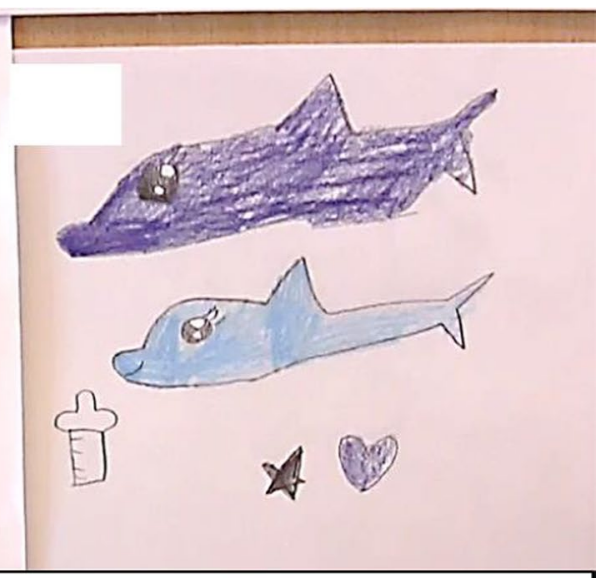

ANDAS GENOM UUTHAL

Animal: The dolphin Length: 1,40 and 4,00

Lives: The sea Eats: fish

Weight: $80 \mathrm{~kg}$

Other: Play with the dolphin Breathes through blowholes

Fig. 4 A child's drawing of two dolphins with cartoon eyes and eyelashes. The drawing includes a baby bottle, a star, and a heart. Categorised as culture and person

a plant in a closed jar with soil and some water. She asked the children to write what they thought would happen to the plant. She drew a simplified illustration of the plant experiment setup on the white board (Fig. 5). The teacher also demonstrated how to divide a page in the notebook in two parts, to leave room for a future drawing of the plant. Since the drawing was reduced to general aspects in terms of detail, colour, and shape, we interpret that the science content was represented as theory. 


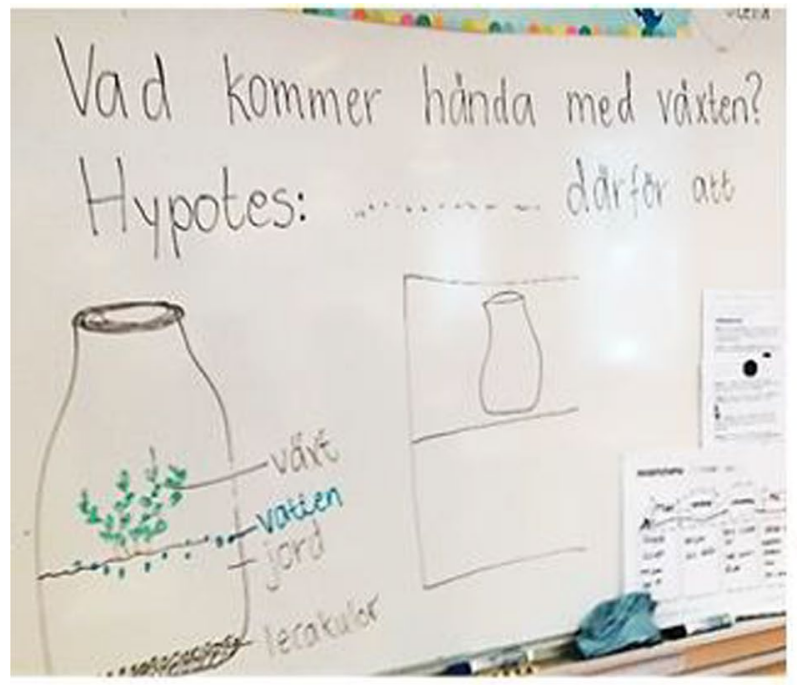

What will happen to the plant?

Hypothesis: .... because

Fig. 5 A teacher's writing and drawing on the white board, including an illustration of the plant experiment setup. Categorised as theory

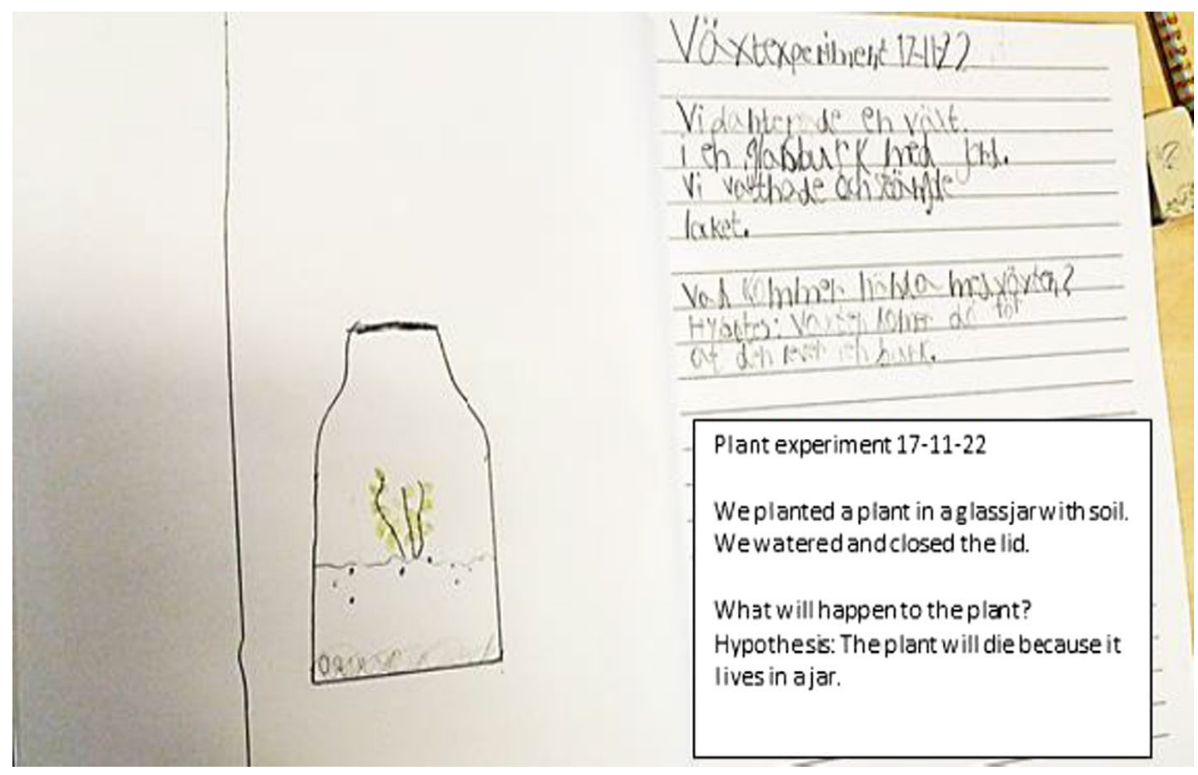

Fig. 6 A child's drawing of the plant experiment setup. Categorised as theory

We collected 16 drawings during this lesson. All the children seemed to have copied the teacher's illustration of the experiment setup, displaying only the most general details, colours, and shapes (Fig. 6). Hence, we interpreted that all the drawings represented the science content as theory. A few of the drawings included a hand-held 


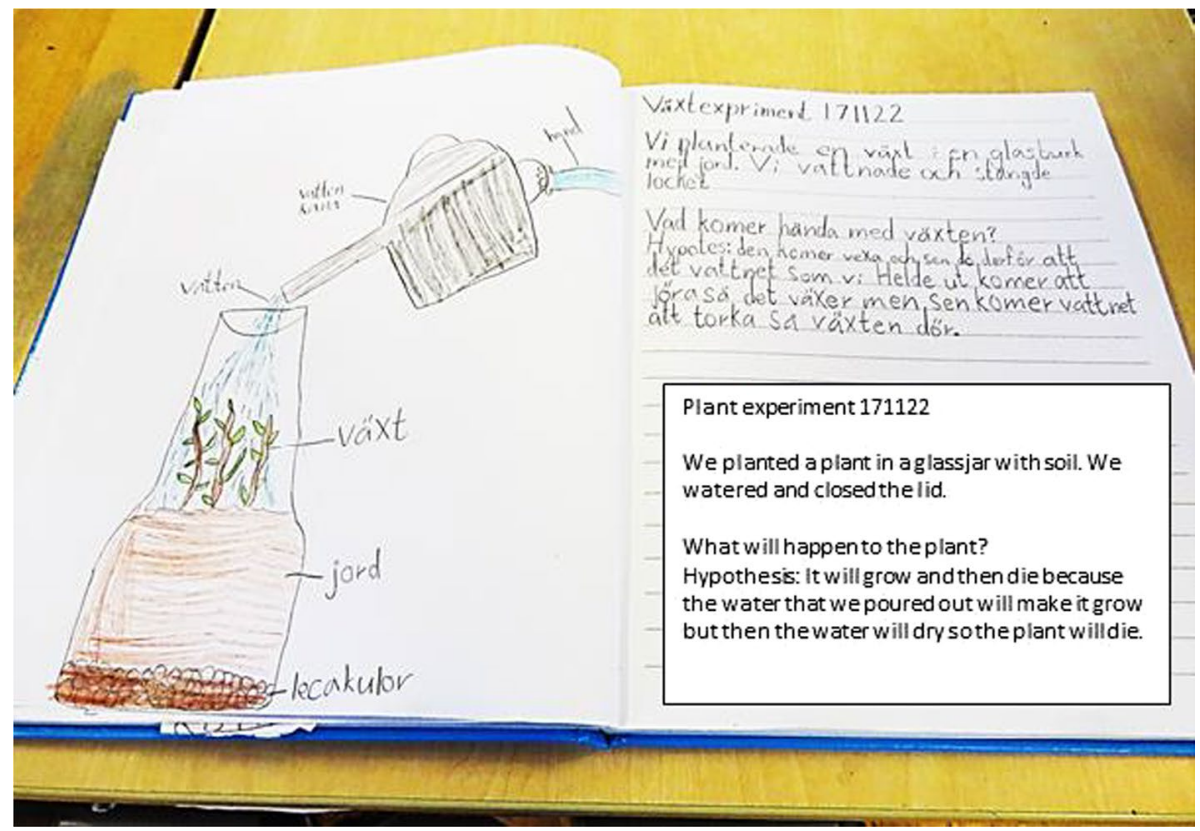

Fig. 7 A child's drawing of the plant experiment setup, with a human-held water can from which water is pouring onto the plant. Categorised as theory and event

watering can with water dripping onto the plant, why they were also categorised as event (Fig. 7).

\section{Story 3: Teacher Does Not Provide Semiotic Resources Related to Visual Representation}

The last example comes from a preschool-class. The observed lesson took place after an outdoor experiment, where the children had tried what it was like to slide down a snowy hill on wood, plastic, fabric, and cardboard paper. Back in the classroom, the teacher and children discussed the outcome of the experiment, and the teacher mentioned the term friction in relation to how easy it is to slide on something. Then the teacher gave children the task to "write friction on the top of the paper and draw something you did outdoors'. She did not provide any semiotic resources related to visual representation during the lesson.

We have analysed nine drawings produced by children during this lesson. One of these did not fit any of the categories. Although most of the remaining eight drawings displayed a view of a snowy hill, they represented the science content in four different ways: as theory, context, art, and event. One example is a drawing that was categorised as theory because it illustrates the four different materials that were central to the experiment, and it places them in a minimalistic setting (Fig. 8). Another drawing displayed three figures pouring oil on the hill (in order to glide faster). This drawing was categorised as event because of the pouring oil and because of the speed lines drawn in relation to the sliding figures (Fig. 9). 


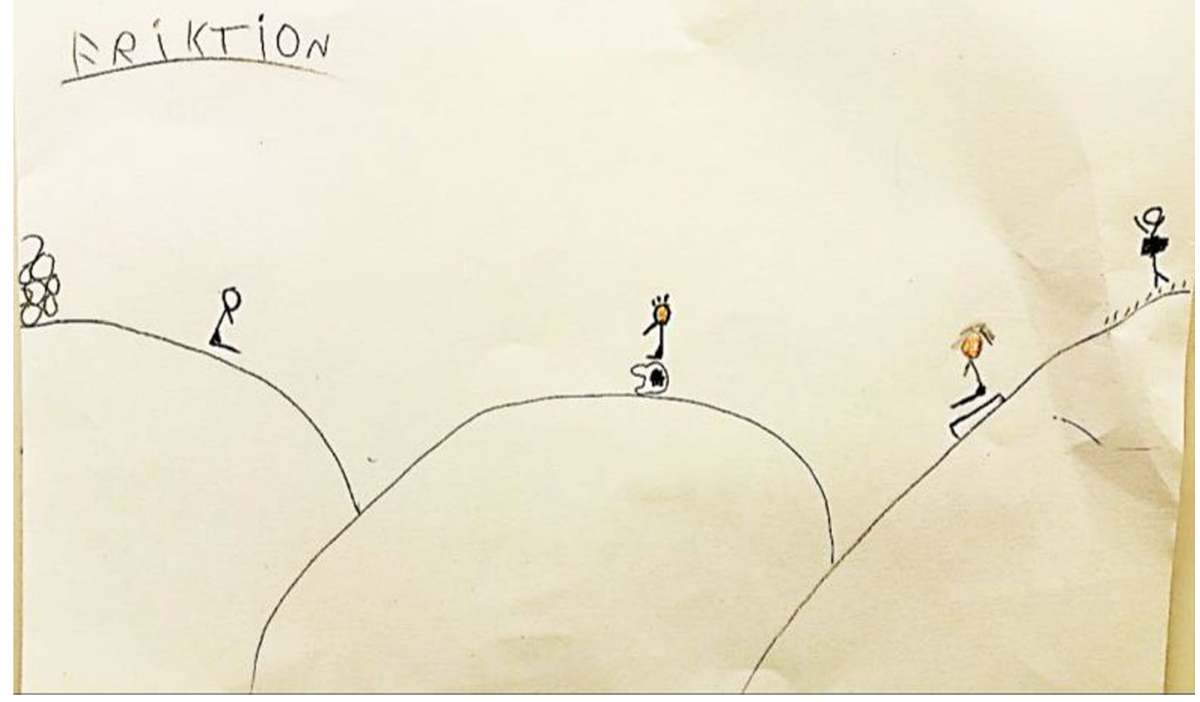

Fig. 8 A child's drawing of figures about to slide down the hill on four different materials. Categorised as theory

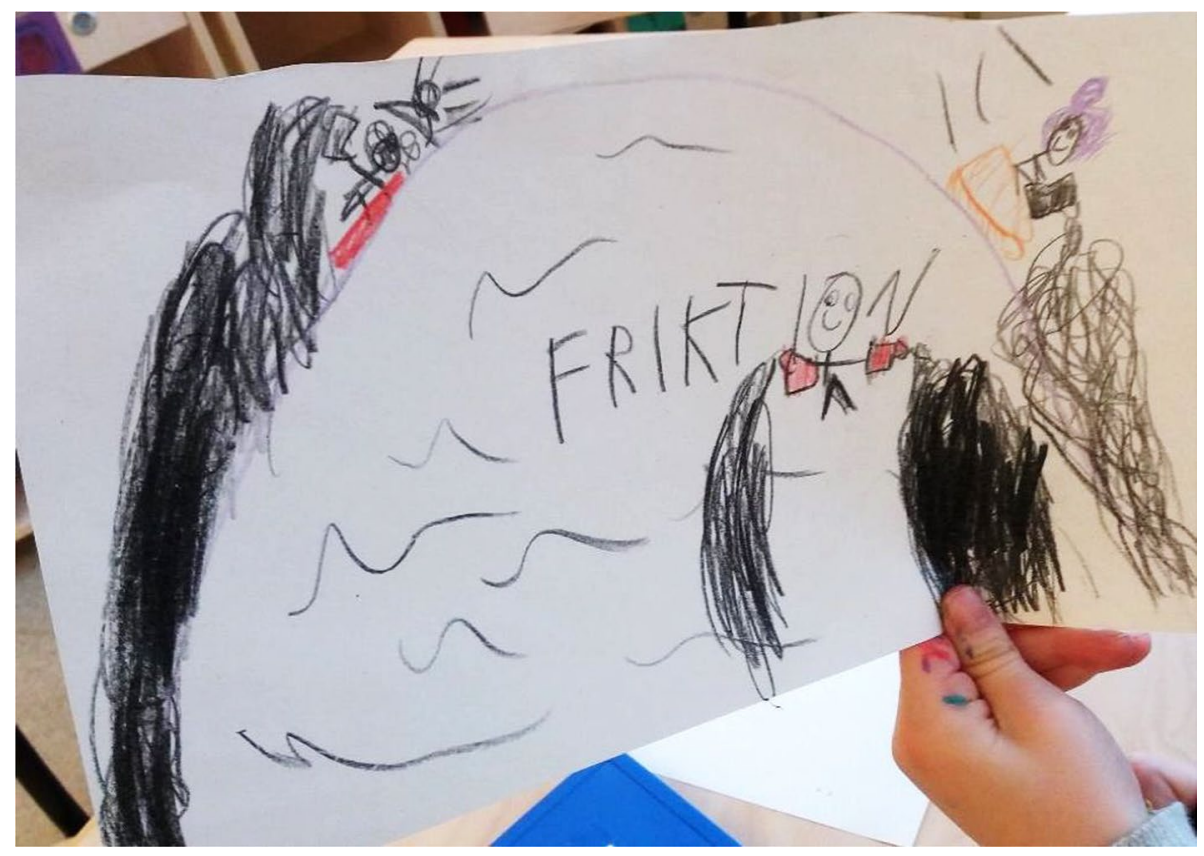

Fig. 9 A child's drawing of three figures pouring oil on the hill (to slide faster), with speed lines behind the sliding figures. Categorised as event 


\section{Discussion and Implications}

Our article shows that teachers' provision of semiotic resources has a large impact on the ways children represent science content in their drawings. The impact may work in two ways. First, teachers can make different choices available to children when they draw in science class, by introducing semiotic resources and ways of representing science content. One example is shown in story 2 , where the teacher draws a schematic picture of an experiment setup on the whiteboard. Here, we judge that the teacher helps the children to foreground the science content, by conveying its most general aspects in terms of shape and colour. Other examples in our data show that teachers provide templates or symbols to support children to foreground the science content in their drawings. Second, the teacher may convey conventions for how to draw in science class, through the semiotic resources they provide. Such conventions seem to be clearly conveyed in story 2 , since nearly all the children represent the plant experiment setup only in the same way as in the teacher's drawing on the whiteboard. Judging from the children's drawings made in story 1 however, conventions for how to draw in science class do not appear to be clearly conveyed. Even though the teacher in story 1 did provide semiotic resources in the shape of non-fiction illustrations and photos of real animals, hence, where science was represented as theory, many of the children drew the animals with human features and included symbols such as hearts and stars in their drawings.

The fact that the teachers in our study primarily provide resources where science is represented as theory, hence as content reduced to its most general aspects in terms of detail, colour, shape, and setting (Westlund, 2018), can be understood as a way of conveying conventions for disciplinary drawing in science (Hoffman and Wittman, 2013). Similar signs can be inferred from previous studies, which show that many children include fun details or embellishments in their drawings, unless their teachers signal that other factors are valued when drawing in science class. While these studies have pointed out that teacher convey conventions for drawing through instructions and classroom dialogue (Danish \& Phelps, 2011) and individual feedback on children's drawing (Danish \& Enyedy, 2007, Ero-Tolliver, Lucas and Schaube 2013), our article highlight that teachers also convey representational conventions through the semiotic resources they provide in the classroom.

Our findings imply that teachers may need to make explicit that their ways of representing science content are not the only acceptable ones. Assuming that meaning making is a process of reshaping information communicated by the teacher in the classroom (Jewitt et al., 2001), there may be little room for children's own meaning making if they seek to represent science content in the same way as in the resources made available by the teacher. If students experience that they can use other semiotic resources, and other ways of representing science content, than those made available by the teacher during the lesson, their range of underlying choices would be wider (cf. Jewitt et al., 2001). Hence, children may experience that they can use more of their repertoire when they try to make meaning of science content in their drawings.

With this article, we want to initiate a discussion about if and how 'emergent disciplinary drawing' should be incorporated as an element of science pedagogy in ECE practice and ECE teacher education. When children draw in science class, their meaning making is not only oriented towards the science content per se, but also towards how to draw in science. We propose that the term 'emergent disciplinary drawing' is used to capture early attempts of using science-specific forms of visual language, different from those used in other school subjects or when drawing for fun. The term is based on the concept of 
emergent disciplinary literacy, which captures early attempts of specialising talking and writing in relation to different school subjects (Björk and Folkeryd 2021). In our view, the term 'emergent disciplinary drawing' highlights that drawing, and not only talking and writing, is a science-specific form of communicating that can be taught and learned. Teaching for emergent disciplinary drawing can involve classroom dialogues on what constitutes a good science representation in terms of detail and accuracy (cf. Danish \& Phelps, 2011). It can also involve discussions of how drawing in science may be different from drawing in other situations, for example, when it comes to using decorations (Ero-Tolliver, Lucas and Schaube 2013) and cartoon techniques (Lundin \& Jakobson, 2014), or adding facial features or other human bodily traits to a non-human science content (Westlund, 2018). Moreover, the teacher can make children aware of some of the drawing conventions that apply in different science disciplines, for example, that colours and symbols signify different properties and relationships in chemistry (Cooper, Stieff, and DeSutter 2017). Finally, teaching can address the role of drawing in the history of science, for example, when it comes to documenting new species (Wittman, 2013) or astronomical phenomena (Nasim 2013). We concur with Shanahan and Shanahan (2014) that disciplinary literacy can be seen as an 'invitation to join a club' (p. 629). Seeing drawing as an essential part of disciplinary literacy, we propose that teaching for emergent disciplinary drawing opens up opportunities for children to engage with science the same way scientists do. In other words, teaching for emergent disciplinary drawing is a way to invite children to join the club of science.

Acknowledgements The research presented here is part of a larger project in which we collaborate with Karin Due and Christina Ottander.

Funding Open access funding provided by Umea University.

Open Access This article is licensed under a Creative Commons Attribution 4.0 International License, which permits use, sharing, adaptation, distribution and reproduction in any medium or format, as long as you give appropriate credit to the original author(s) and the source, provide a link to the Creative Commons licence, and indicate if changes were made. The images or other third party material in this article are included in the article's Creative Commons licence, unless indicated otherwise in a credit line to the material. If material is not included in the article's Creative Commons licence and your intended use is not permitted by statutory regulation or exceeds the permitted use, you will need to obtain permission directly from the copyright holder. To view a copy of this licence, visit http://creativecommons.org/licenses/by/4.0/.

\section{References}

Ainsworth, S., Prain, V., \& Tytler, R. (2011). Drawing to learn in science. Science, 333(6046), 1096-1097.

Änggård, E. (2005). Barns bildskapande - en del av förskolebarns kamratkulturer [Making Pictures - a part of preschool children's peer cultures]. Doctoral dissertation. Linköping University, Sweden.

Björk, O., \& Wiksten Folkeryd, J. (2021). Emergent literary literacy. L1-Educational Studies in Language and Literature, 20, 1-25. https://doi.org/10.17239/L1ESLL-2021.21.01.03

Cooper, M. M., Stieff, M., \& DeSutterc, D. (2017). Sketching the invisible to predict the visible: From drawing to modeling in chemistry. Topics in Cognitive Science, 9, 902-920.

Danish, J. A., \& Enyedy, N. (2007). Negotiated representational mediators: How young children decide what to include in their science representations. Science Education, 91(1), 1-35.

Danish, J. A., \& Phelps, D. (2011). Representational practices by the numbers: How kindergarten and firstgrade students create, evaluate, and modify their science representations. International Journal of Science Education, 33(15), 2069-2094.

Danish, J. A., \& Saleh, A. (2015). The impact of classroom context upon 1st and 2nd grade students' critical criteria for science representations. Instructional Science, 43, 665-682. 
Ero-Tolliver, I., Lucas, D., \& Schauble, L. Young children's thinking about decomposition: Early modeling entrees to complex ideas in science. Research in Science Education, 43(5), 2137-2152.

García Fernández, B., \& Ruiz-Gallardo, J. R. (2017). Visual literacy in primary science: Exploring anatomy cross-section production skills. Journal of Science Education and Technology, 26, 161-174.

Hoffmann, H., \& Wittmann, B. (2013). Introduction: Knowledge in the making: Drawing and writing as research techniques. Science in Context, 26(2), 203-213.

Jewitt, C., Kress, G., Ogborn, J., \& Tsatsarelis, C. (2001). Exploring learning through visual, actional and linguistic communication: The multimodal environment of a science classroom. Educational Review, 53(1), 5-18.

Kress, G., Jewitt, C., Ogborn, J., \& Tsatsarelis, C. (2001). Multimodal teaching and learning: The rhetorics of the science classroom. Continuum.

Kress, G., \& van Leeuwen, T. (1996). Reading images: The grammar of visual design. Routledge.

Lundin, M., \& Jakobson, B. (2014). Situated meaning-making of the human body: A study of elementary school children's reasons in two different activities. Cultural Studies of Science Education, 9(1), $173-191$.

Mešić, V., Mahmutović, S., Hasović, E., \& Erceg, N. (2017). Free-body diagrams and problem solving in mechanics: An example of the effectiveness of self-constructed representations. European Journal of Physics Education, 7(3), 53-67.

MODE (2012). Glossary of multimodal terms. https://multimodalityglossary.wordpress.com/ Accessed 10 January 2020.

Monteira, S. F. (2017). O desenvolvemento das prácticas científicas de construción e uso de modelos $e$ probas: un estudo lonxitudinal en educación infantil [The development of the scientific practices of building and using models and evidence: a longitudinal study in Early Childhood Education]. Doctoral dissertation. Universidade de Santiago de Compostela, Spain.

Nassim, O. W. (2013). Extending the gaze: The temporality of astronomical paperwork. Science in Context, 26(2), 247-277.

Shanahan, T., \& Shanahan, C. (2014). The Implications of disciplinary literacy. Journal of Adolescent \& Adult Literacy, 57(8),

Skolverket (2019). Inskrivna barn 2009-2019, andel av barn i befolkningen [Enrolled children 2009-2019, share of children in the population]. https://www.skolverket.se/skolutveckling/statistik/sok-statistikom-forskola-skola-och-vuxenutbildning Accessed 27 November 2020.

Westlund, E. (2018). Visual formation of science content in young students' multimodal compositions Seven content representations. Journal of Visual Literacy, 37(4), 294-316.

Wittman, B. (2013). Outlining species: Drawing as a research technique in contemporary biology. Science in Context, 26(2), 363-439.

Publisher's Note Springer Nature remains neutral with regard to jurisdictional claims in published maps and institutional affiliations. 